\title{
UNCERTAINTY VISUALIZATION APPROACHES FOR 3D MODELS OF CASTLES RESTITUTED FROM ARCHEOLOGICAL KNOWLEDGE
}

\author{
T. Landes ${ }^{1}$, M. Heissler ${ }^{2}$, M. Koehl ${ }^{1}$, T. Benazzi ${ }^{1}$, T. Nivola ${ }^{1}$ \\ ${ }^{1}$ Photogrammetry and Geomatics Group, ICube Laboratory UMR 7357, INSA Strasbourg, France \\ (tania.landes, mathieu.koehl, theo.benazzi, thibaut.nivola)@insa-strasbourg.fr \\ ${ }^{2}$ Cultural Heritage Service, County Council of Bas-Rhin \\ (mathias.heissler@bas-rhin.fr)
}

Commission II

KEY WORDS: Restitution, Uncertainty, visualization, Archeological knowledge, Point Cloud, Assessment, reliability

\begin{abstract}
:
In the cultural heritage field, several specialists like archaeologists, architects, geomaticians, historians, etc. are used to work together. With the upcoming technologies allowing to capture efficiently data in the field, to digitize historical documents, to collect worldwide information related to the monuments under study, the wish to summarize all the sources of data (including the knowledge of the specialists) into one 3D model is a big challenge. In order to guarantee the reliability of the proposed reconstructed 3D model, it is of crucial importance to integrate the level of uncertainty assigned to it. From a geometric point of view, uncertainty is often defined, quantified and expressed with the help of statistical measures. However, for objects reconstructed based on archaeological assumptions, statistical measures are not appropriate. This paper focuses on the decomposition of 3D models into levels of uncertainties (LoUs) and on the best way to visualize them through two case studies: the castle of Kagenfels and the Horbourg-Wihr Castellum, both located in Alsace, France. The first one is well documented through still ongoing excavations around its remains, whereas the second one disappeared under the urbanization of the city. An approach enabling, on the 3D models, not only to quantify but also to visualize uncertainties coming from archaeological assumptions is addressed. Finally, the efficiency of the approach for qualifying the proposed 3D model of the reconstructed castle regarding its reliability is demonstrated.
\end{abstract}

\section{INTRODUCTION}

The process of 3D modeling of cultural heritage buildings requires the combination of data coming from several sources. Depending on the conservation state of the building, the geometric acquisition based on surveying measurements is primordial first step. However, with the purpose of restituting the building in its original stage, it is often necessary to complete the model with supplementary material or knowledge, coming usually from archaeologists or architects working on those sites.

Restitution projects use increasingly the process of digital modeling as a means of interactive presentation and interpretation.

Models are no longer limited to 2D renderings, but are now based on advanced 3D or 4D modeling techniques. This brings up new questions about the handing of the model quality. In order to evaluate the quality of a 3D model, an error budget might be elaborated. It is rather easy to assess the quality of the model from a geometric point of view, when restitution relies on measurements. However, when there is a lack of tangible data and the restitution is mainly based on archaeological knowledge or hypotheses, the way to quantify the uncertainties related to the reconstructed object remains a challenge. For some authors, a lack of certainty might even be detrimental as the models imply a kind of truth, which may hinder further interpretation and analysis (Sylaiou et al., 2009).

Concerning evaluation and representation of uncertainties in 3D models base on archaeological knowledge, papers proposed in the literature do not solve this problem universally. The methods used are various and usually adapted to the specific site under study. Depending on the project, the available data and the objectives followed, the most effective means of representation of the geometry and of the uncertainty of the $3 \mathrm{D}$ model must be chosen.

This paper presents firstly a state of the art dealing with the quantification and the representation of uncertainties for 3D models based on archaeological knowledge. Then, applied to two case studies, an approach enabling not only to quantify but also to visualize uncertainties will be addressed.

\section{RELATED WORK}

The accuracy of the restitution process has given rise to much debate within the archaeological community (Barrat, 2016). The first difficulty comes from the fact that there is often a lack of consistent methodology for restitution, mainly because of the lack of a standard in data production. The reconstruction of partially or totally destroyed structures might rely on data from heterogeneous sources (Rodríguez-Gonzálvez et al., 2017). Indeed, metric data acquired on site might be completed with multitude of historical documents that often have non-metric properties (historical maps, old photographs, drawings, sketches, paintings) as well as archaeological knowledge based on deductions (existence of elements based on castles constructed in the same period by probably the same architects).

Therefore the quality, accuracy and completeness of restitution depend on the way these heterogeneous data are combined. Apart from the fact that these data are non-metric, they also 
often lack objectivity and are usually the result of an interpretation made at a given moment. Moreover, they might not be up-to-date due to later discoveries. There is therefore of crucial importance to work in close collaboration with archaeologists and heritage architects during the whole process of $3 \mathrm{D}$ reconstruction.

While it is fairly easy to quantify the uncertainty of a measurement or a 3D survey, it is more difficult to qualify nonmetric data. In the engineering field, uncertainties of metric elements are expressed through statistical values (standard deviations, root mean square errors, histograms, etc.). When representing elements (in 2D or 3D), like archaeological sites which are no longer measurable (disappeared or destroyed) or which existence result from hypothesis, a solution consists in using a visualization process. Not only the chronological dating might in some cases be uncertain, but also the position of the discovered object. Obviously missing data is a major component of uncertainty (Zuk et al, 2005). In addition, the degree of uncertainty varies considerably from one project to the other (Barrat, 2016). Any proposal relating to archaeological data therefore contains uncertainties. This uncertainty must be integrated into any visualization not only for transparency purposes but also to improve the cognitive task of spatio-temporal understanding.

For visualizing uncertainties, we might use several colors or textures, degrees of transparency (Bertin, 2010). For instance, several degrees of transparency allow to emphasize the parts of the model which are assumptions (transparent) from those which existence is proven (opaque). However, experiments will show that the use of transparency makes the model sometimes difficult to understand, especially when it is of complex geometry with a lot of superimposed elements. Another solution consists in mixing several levels of details (LoD), i.e. a simplified geometry for objects which knowledge is uncertain against very high LoD and high resolution texturing for objects which level of knowledge is very high. Whatever the adopted solution, when we move from quantified uncertainty to visualized uncertainty, we obviously simplify the uncertainty to make it compatible with the visual channels, which are limited.

Whereas Gutierrez et al (2006) and Freiman and Gillings (2007) focus on realism at the expense of representing uncertainties, Dell'Unto et al (2013) partially abandon visual realism in favour of the development of a colour coded uncertainty scale. The authors suggest representing the virtual hypothesis with markers indicating different levels of consistency, in order to map how the different reconstructed structures relate to the archaeological evidences.

Kensek (2007) presents a review of the methods used in many disciplines to represent uncertainty in reconstructions, which include colouring schemes and shadings, hatching, and line types, rendering techniques or levels of transparency to distinguish easily missing and reconstructed data. Some of these methods have been successfully applied in the field of architectural and archaeological virtual reconstruction.

Although the issue of assessing and representing the uncertainty of more or less hypothetical elements composing a reconstructed 3D model is discussed in many bibliographical references, it remains impossible to solve this problem universally. However, a classification in several levels of uncertainties (LoU) seems to be realistic. This solution requires a decomposition of the uncertainty related to the element to assess, ranging from pure assumptions (high LoU) to a very high level of archaeological knowledge, i.e. the existence of the element (low LoU).

In order to assess the suggested methodology of uncertainty decomposition and visualization, our approach has been applied on two study cases: the first one is a castle which has been restituted in 3D based on existing remains and objects found during several decades of excavations; the second one is a military construction from which nothing tangible remains. In order to understand the complexity of assigning a level of uncertainty, it is important first to describe the data on which both modelling processes have been based.

\section{STUDIED CASTELS}

\subsection{Kagenfels' castle}

The first case of study concerns a castle located in the forest of Obernai-Bernardsviller, Alsace, France. First stones of the Kagenfels' castle have been laid in the middle of the XIII ${ }^{\text {th }}$ century, around 1262. Several phases of construction gave birth to the castle in its final version, until the end of the $\mathrm{XVI}^{\text {th }}$ century. In 1999, when archaeological and deforestation work began, the site of Kagenfels was like an impressive cone of scree, where only few masonry remains were visible. The castle is almost entirely ruined, but its recovered history revealed that the site has probably never been looted. Therefore, the cone of scree was of crucial importance, because the architectural elements were supposed to be present on site.

\section{Survey of the site and the castle's remains}

With the aim of reconstructing the castle in $3 \mathrm{D}$, even if only a part of the structure remains, first of all, it was necessary to record the site in its current state. In this context, photogrammetric and terrestrial laserscanning campaigns have been carried out. Terrestrial laserscanning with Faro X330 scanner allowed obtaining a point cloud of 40 million points on the area. Terrestrial photogrammetric survey with a Canon EOS 700D (CMOS image sensor of $18 \mathrm{MP}$ ) has provided 850 photographs. Since the surrounding area gives also valuable information on the defensive system, not only the castle's remains but also about 1 square kilometer of the surrounding area has been captured through about 2000 photos by UAV (DJI Phantom 3, with CMOS image sensor of $12 \mathrm{MP}$ ). These data helped us to capture the upper parts of the remains, which could not be scanned from the ground. After processing of the whole datasets, a 3D model of the ruins and their surroundings has been obtained (Figure 1). The geometric accuracy of the final mesh model is about $3 \mathrm{~cm}$.

\section{Geo-localized inventory of architectural remains}

Through the study of the collapses of this castle of modest size, it was conceivable to restore graphically the elevations of the disappeared facades. An exhaustive and geo-localized inventory of the architectural elements has therefore be undertaken. More than 1500 blocks have been found in the field around the remains of the Kagenfels' castle during the last 23 years of excavations. Every block in this 2500 square meters area has been recorded and located on a map (Figure 2). This work has been done in $2 \mathrm{D}$ on that map, but also in depth in the screes and in height compared to the level of abandonment of the castle. This three-dimensional inventory makes it possible to develop a rigorous analysis allowing to restore the initial location of each 
architectural element. This original method, implemented during 19 years, is one of the specificities of the Kagenfels site. It is based on the current spatial distribution of "series" of scattered blocks coming from the same architectural ruined site.

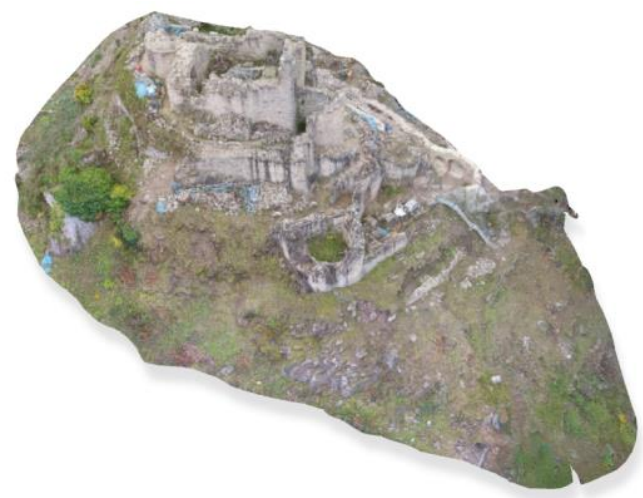

Figure 1: 3D model as textured mesh model of the Kagenfels' remains in its current stage (end 2017), on about $80 \mathrm{~m}$ x $60 \mathrm{~m}$.

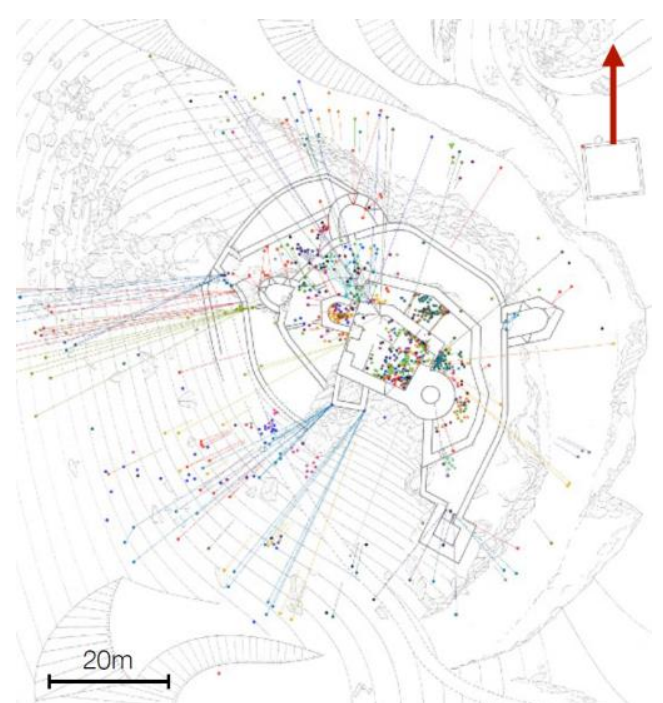

Figure 2: Location plan of inventoried blocks (Mathias Heissler, 2007); each color represents a specific "series" of blocs

All blocks and lapidary fragments belonging to the same architectural element, like doors, windows or arrow loops for instance constitute a "series". Each discovered block or fragment thus receives a double identification, composed of the discovery number and a serial number referring to the part of the castle it belongs to. Each series of blocks is described in detail in a specific summary sheet describing the nature of the architectural element, its characteristics, its dimensions, the three-dimensional localization of the blocks and fragments assigned to it, and obviously photographs of the elements.

The compilation of several summary sheets of series gathering the elements relating, for example to the north facade of the house, enables to conclude to the presence of a facade of four floors. This method of recording has already made it possible to offer graphic representations of the north, east and west facades of the house, as well as several towers of the castle including multiple arrow loops. This inventory gives, indirectly, information on the partitions and the internal organization of the house. As a consequence, 16 years ago the heritage architect in charge of the excavations was already able to propose a graphical representation of the ruined elevations (Figure 3).

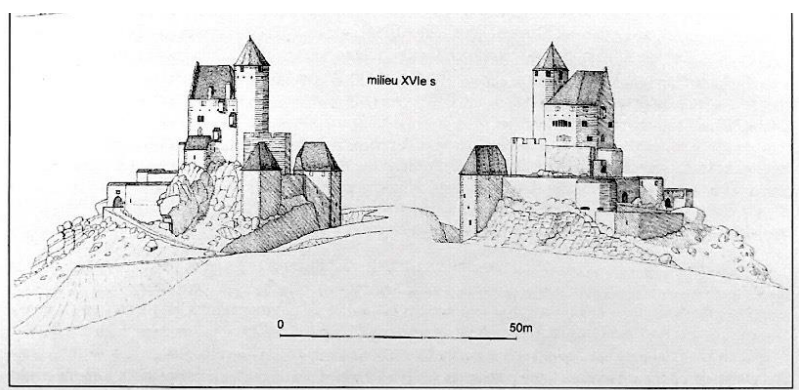

Figure 2: Proposition of graphical restitution of the castle in 1550 (by Mathias Heissler, 2002)

The graphical and documentary databases available today for the restitution of the castle are summarized in Figure 3.

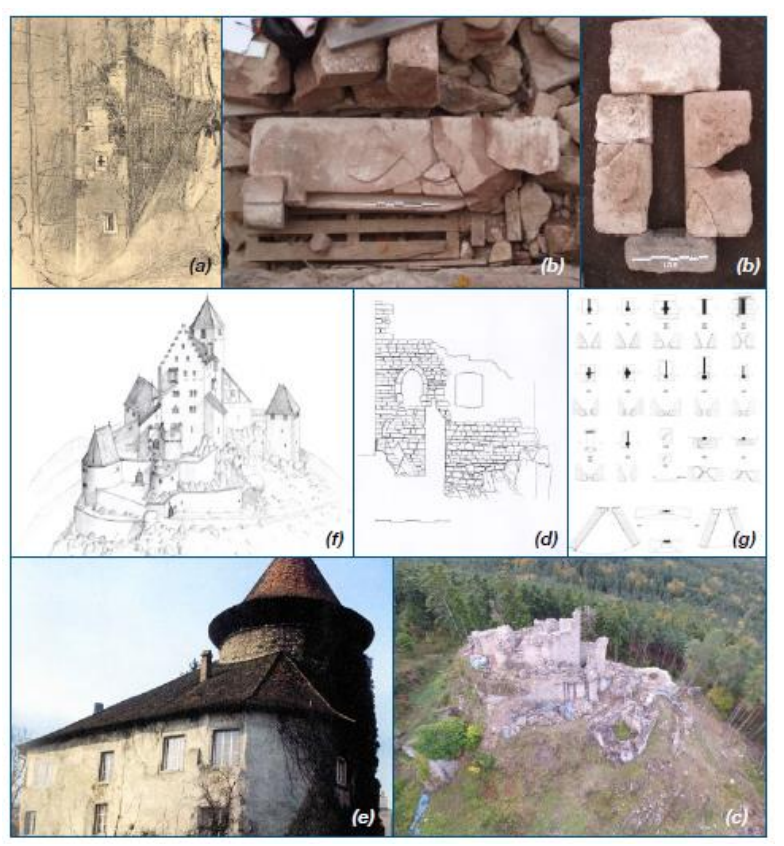

Figure 3: Collected data as a support the modeling (a) iconographic documents; (b) and (c) photographs; (d) digitalization on orthophotos; (e) photographs of similar sites or roof structures; (f) and graphical restitution propositions

\section{Similar sites in terms of geography and of time period}

Several ruins are located in the surroundings of the Kagenfels' castle and some of them have been built in the second half of the $13^{\text {th }}$ century. The castle of Haut-Andlau (Landes et al., 2007) located in Andlau (Alsace, France) can be considered as a precious reference site because this castle is almost entirely preserved in elevation. Its roofs have also been conserved until the end of the $18^{\text {th }}$ century. For this reason, rich iconography describes the castle in a state which is close to its initial state, with hoardings and roofs.

Regarding spatial organization and architectural details, the ruins of other neighbouring castles (Birkenfels, Dreistein, Ortenbourg) present many similarities with Kagenfels. They constitute local references for typologies of windows, especially the large windows with multiple rectangular fenestrons, for example. In the past, same typologies of windows were used quasi-systematically in a same geographical area. 


\section{Production of the 3D models}

By cross-referencing and analyzing all data collected in the field for almost 20 years, i.e. geometrical, historical, constructive and aesthetic rules, and archaeological data, as well as the metric data acquired during the surveying campaign, a reliable 3D reconstructed model of the castle as it was in the XVIth century has been constructed in the Sketchup software (Figure 4). The whole processing chain dedicated to the modeling of the castle and its surroundings has required approximately 350 production hours. This model, firstly without texture, results from a very efficient but laborious and time consuming collaboration between geomaticians and a heritage architect who works for 25 years with volunteers at the preservation of the castle.

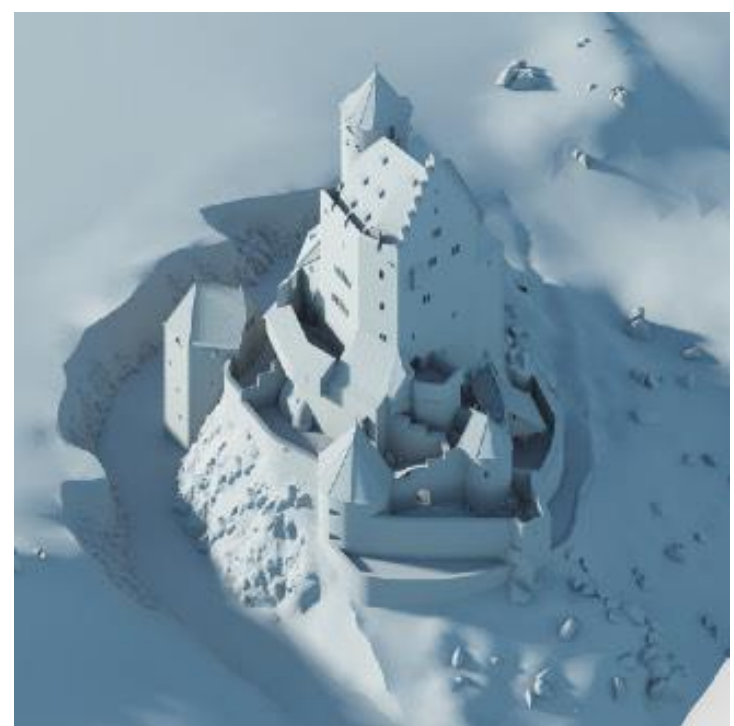

Figure 4: 3D reconstructed model suggested for the Kagenfels castle, as it was in 1550

For communication purpose, also a rendered model has been realized in the Lumion software (Figure 5) and integrated in a virtual reality (VR) system to allow immersive visits. Apart from the impressive impact, the immersive virtual visit of the restituted castle allowed to correct some parts of the model, like positions of arrow loops, which could be refined after simulating the sniper position.

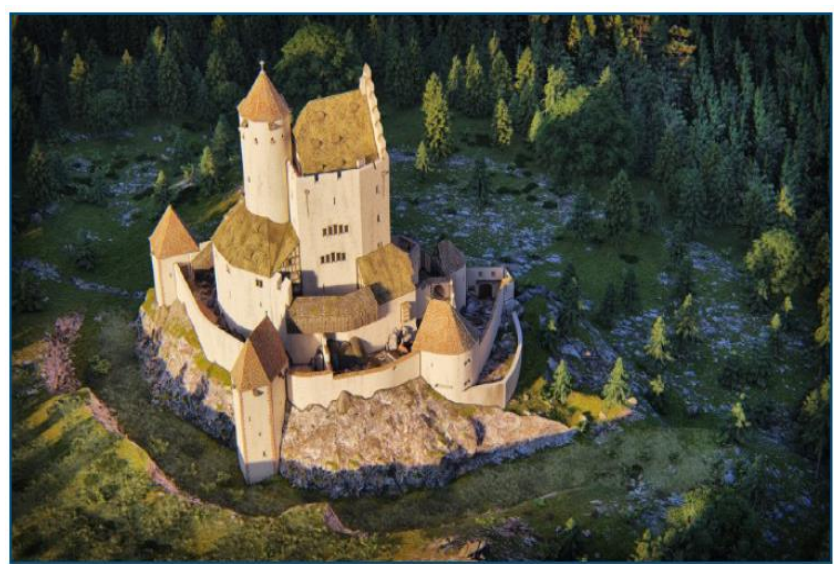

Figure 5: photo-realistic rendering of the Kagenfels' 3D model (Benazzi, 2017)

The way the levels of uncertainty have been integrated to the process of restitution is explained in section 4 .

\subsection{Horbourg-Wihr's castellum}

A second case of study concerns a castellum of the IV $^{\text {th }}$ century situated in Horbourg-Wihr, Alsace, France. It disappeared under the urbanization of the city of Horbourg-Wihr but is known thanks to numerous archaeological works led for the 19th century, with important excavations realized by E.A Herrenschneider and architect C. Winkler during years 188485. Their investigations allowed to draw up a plan of the castellum. Many more excavations were since realized and others are still programmed to try to learn more about the history of the city. Figure 5-(a) represents the theoretical 2D plan of the castellum of Horbourg-Wihr drawn up by E.A Herrenschneider in 1894. The same excavations also concerned the 16th century castle of Horbourg-Wihr, which appears in the northeast corner of the castellum Figure 6-(b) is a graphical representation of castellum proposed by architect C. Winkler in 1905.

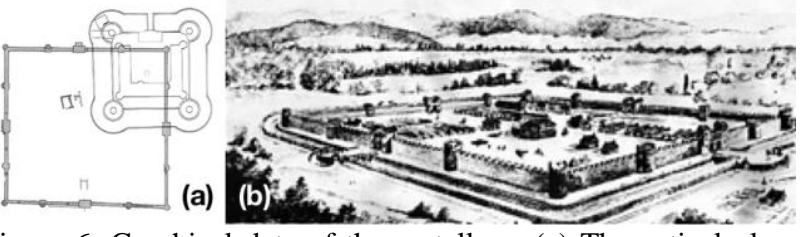

Figure 6. Graphical data of the castellum; (a) Theoretical plan of the castellum and the castle of Horbourg-Wihr, prepared by E.A. Herrenschneider (1894); (b) Horbourg-Wihr's castellum elevation, according to architect C. Winkler (1905).

What is known today about the geometry of this castellum is listed in Fuchs (1996):

- The building forms a quasi-regular quadrangle and its sizes are of 170 meter in the East, 172 meter in the South, 166 meter on the West and 172 meter in the North, by measuring from the external face of the rampart; and its surface is 2,87 hectares.

- Four round towers are located in the angles of the castellum.

- Two simple entrances are present in the middle of the north and south sides of the rampart and two double entrances are located in the middle of east and west sides.

- Two rectangular towers are placed on both sides of every entrance of the castellum for a total of eight towers on the whole perimeter of the rampart.

- Eight intermediate half-round towers complete the defense system and are positioned between entrances and angle towers. - Nothing is known about the internal arrangement of the camp except the existence of a temple having preceded the construction of the castellum.

In summary, the available data are plans and sketches realized by the architect $\mathrm{C}$. Winkler, the reports and photos stemming from archaeological excavations, a drawing from a restitution work of P.Y. Videlier (2016), point clouds from the acquisition of a few retrieved blocks, a publication describing the castellum, some information about its size by Fuchs (1996) and finally the theoretical plan of E.A. Herrenschneider (1894).

The planimetric sizes of the angle-towers, intermediate towers and entrance-towers could be determined from archaeological excavations and from theoretical plan drawn up from these. Concerning the temple, the archaeological excavations of $1884 / 85$, then of 2004 allowed to bring up-to-date its foundations. A capital of the Tuscan order was found by E.A. Herrenschneider in 1884 and elements of ledge and molding were also found in re-use. 


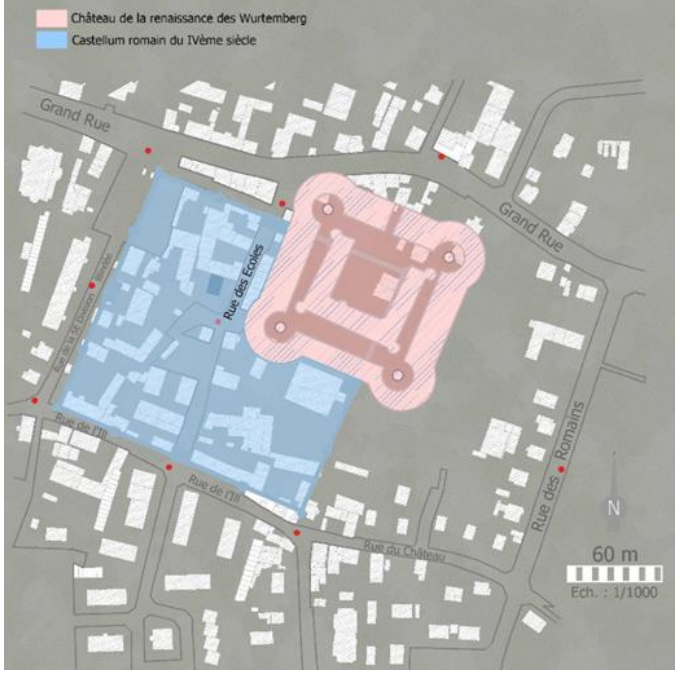

Figure 6: Schematic of the castellum and $16^{\text {th }}$ Century castle (topographic map dating from 1900 repositioned on the cadastral background of Horbourg-Wihr)

\section{Similar sites in terms of geography and of time period}

Close similar sites in terms of architecture, geographical location and of time-period were visited to be inspired by them. In Germany, the sites of Alzey, Bad Kreuznach, Boppard and Saalburg present similar Roman vestiges. In Switzerland, the sites of Avenches, Kaiseraugst, Windisch and Yverdon-les-Bains also present similarities. Information could thus be collected by the visit and can be enumerated:

- The choice of the organisation of the camp is finally a mixture of both types of organisation, namely: i) The model via singularis: with a passage along internal side of ramparts and around barracks; ii) The model of barracks organisation leaned in ramparts: with one free central space, as it can be observed on the Alzey's site.

- The choice of the texture of the walls is inspired by the Windisch remains.

- Buildings were modelled and inspired by the sites of Saalburg and Windisch.

- The thickness of walls and a part of the rises of certain towers were preserved on the camp of Boppard, which is of the same time-period as that of Horbourg-Wihr. That's why the information to restore the thickness of the walls of towers has been taken from this site and that of Yverdon-les-Bains.

Other restitutions of castella like the restitution of the castrum of Yverdon-les-Bains, or of the museum of Bad Kreuznach or Kaiseraugst allowed to propose a model of the internal organization of the camps, for which no information was highlighted during archaeological excavations with the exception of that of the temple.

\section{Production of the 3D models}

The virtual model of the castellum of Horbourg-Wihr has been realized based on the various types of data presented previously and from architectural hypotheses. Indeed, the available data being incomplete, it is not possible to restore buildings in detail and in a homogeneous way. To model these buildings in 3D, it was thus essential to lean on the knowledge and the hypotheses of the archaeologists.

It is important to mention that the first aim of the restitution project was to highlight this historic disappeared site of the municipality of Horbourg-Wihr. The main objective was to make discover the site to the visitors and to the inhabitants. The 3D modelling allowed ending in a 3D model proposal, developed gradually in dialogue with archaeologists who studied and worked more than 20 years on the concerned building (Figures 7 and 8).

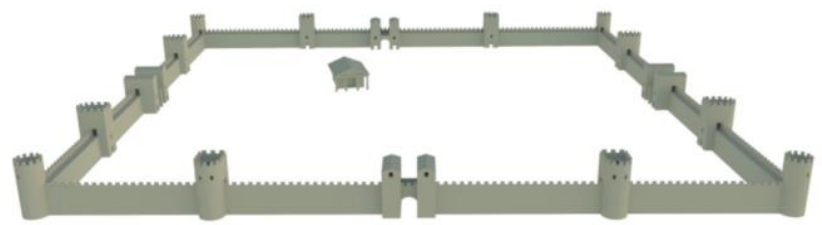

Figure 7: 3D model of the castellum without texture.

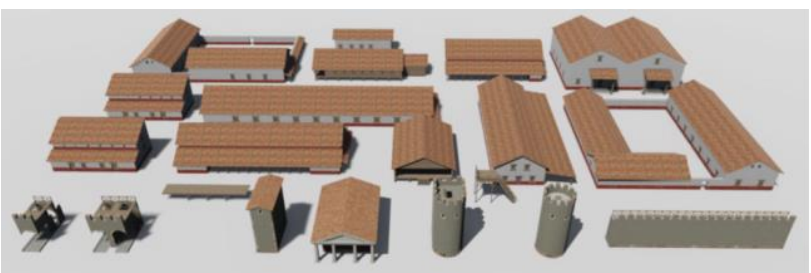

Figure 8: Castellum main component library

The objective was not only to propose a depiction in photorealistic images of the building, but also to set up interactive solutions of accessible valuation for the public. For that purpose, the solution chosen to discover the site was to realize a virtual visit, allowing the user to see the building since nine points of view in the city. This virtual visit allows to discover the site in an interactive way and to learn more on its history thanks to the integration of texts, images and videos (Panotour software).

The 3D model has been put online, in order to allow the public to explore the castellum interactively. Figure 9 shows the results on the Sketchfab plateform, which gives also the possibility to visualize the model in VR in the scale 1 to 1 .

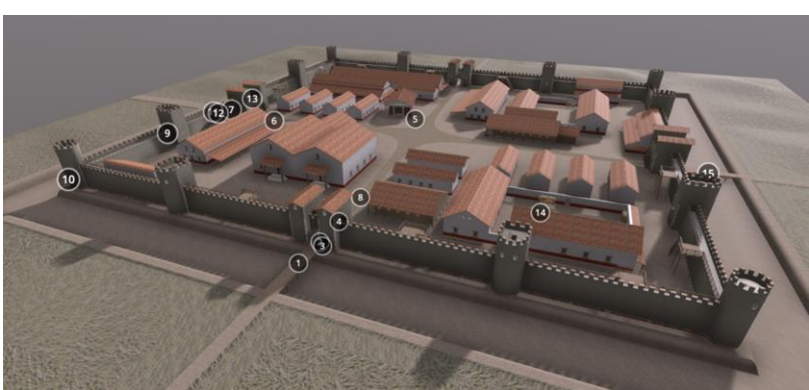

Figure 9: 3D model of the Calstellum on Sketchfab platform (Nivola, 2017)

In parallel to the 3D model productions of both castles described in this section, another stake of both projects was to succeed in modelling the building although archaeological knowledge and data were sometimes incomplete. Thus an approach allowing reporting uncertainties of restitution, bound to the reliability of the data has been developed and is presented in next section. It allows to be transparent regarding the modelling method and to keep a "traceability" of the choices made during the restitution. 


\section{UNCERTAINTY VISUALISATION APPROACH}

Since both castles do not benefit from the same amount of available data, the way the uncertainties have been managed in each model is described for each one, separately. However the same visualization approach has been adopted, i.e. a representation in color gradients from red to green.

\subsection{Kagenfels' castle}

In order to evaluate the degree of uncertainty of the reconstructed castle, firstly the $3 \mathrm{D}$ model had to be structured in characteristic geometrical and semantical parts. To facilitate the future update of the model, each object has been modeled independently and in a structured way in a common repository.

Then we confronted the nature of the elements composing the castle (wall, roof, frame, etc.) with the level of knowledge associated to this element. This correspondence is a very challenging task.

In a first stage, for every recorded element (door, window frames, etc.), we planned to represent two uncertainties criteria simultaneously: a) uncertainty related to the geometry of the element (dimensions, shape); b) uncertainty related to their positioning on the structure.

Obviously, only one visual channel is available to represent these two informations. That's why a first experiment consisted in introducing a radiometric gradient (from red to green) to represent the geometric uncertainty and to use a degree of opacity (from transparency to opacity) to represent the positioning uncertainty. As expected, the resulting classes were not trivial to distinguish on the display. After investigations, we concluded that both variables are correlated. A well-known object results from the assembly of several fragments found on a specific location. Thanks to the "series", the location of the fragments related to the collapse sequence and given by the stratigraphic analysis allows to deduce the original location of the object on the castle. Therefore, we decided to merge both variables and to define five LoUs, ranging from simple supposition (highest LoU) to a very high level of knowledge (lowest LoU). Finally, a representation highlighting these five levels decomposed in a color gradient from red to green is proposed.

In this context of classifying the elements of the castle according to the level of knowledge assigned to them, the collaboration with the archaeologist in charge of the project was essential.

The work of assessing the five LoU of more than 300 elements composing the $3 \mathrm{D}$ model has been reported in an assessment table, from which Table 1 presents one line. For the specific case of a wall, Table 1 shows the way the knowledge associated to a wall might be considered as a "pure assumption" (red), as "weak" (orange), as "moderate" (yellow), as "high" (green) and as "very high" (dark green).

In order to apply the result of that assessment work on the 3D model, it has been decided to duplicate the final model depicted in Figure 5, to remove all the textures assigned and to apply one of the five colors considered to represent the uncertainty of the element (Figure 10).

Also the elements constructed based on cross-referencing to other castles of the same period had to be affected to one of these classes. For example, figure 10 shows that all timber and gables are assigned to LoU5, whereas the castle's walls remain and belong therefore to LoU1.

\begin{tabular}{|c|c|c|c|c|c|}
\hline & \multicolumn{5}{|c|}{ Level of knowledge } \\
\hline & $\begin{array}{c}\text { Pure } \\
\text { assumption } \\
\text { (LoU5) }\end{array}$ & $\begin{array}{c}\text { Weak } \\
\text { knowledge } \\
\text { (LoU4) }\end{array}$ & $\begin{array}{l}\text { Moderate } \\
\text { knowledge } \\
\text { (LoU3) }\end{array}$ & $\begin{array}{c}\text { High } \\
\text { knowledge } \\
\text { (LoU2) }\end{array}$ & $\begin{array}{l}\text { Very high } \\
\text { knowledge } \\
\text { (LoU1) }\end{array}$ \\
\hline Wall & $\begin{array}{c}\text { No remain, } \\
\text { nor } \\
\text { iconography } \\
\text { or } \\
\text { document. } \\
\text { But } \\
\text { supposed to } \\
\text { exist for } \\
\text { defensive, } \\
\text { structural or } \\
\text { formal } \\
\text { necessities }\end{array}$ & $\begin{array}{c}\text { Remain of } \\
\text { low height } \\
(<1 \mathrm{~m}) \text {. But } \\
\text { no data } \\
\text { about initial } \\
\text { height nor } \\
\text { shape or } \\
\text { function of } \\
\text { the wall }\end{array}$ & $\begin{array}{l}\text { Remain of } \\
\text { more than } 1 \\
\text { m. But no } \\
\text { data about } \\
\text { initial } \\
\text { height, nor } \\
\text { shape or } \\
\text { function of } \\
\text { the wall }\end{array}$ & $\begin{array}{c}\text { Proven } \\
\text { existence } \\
\text { with } \\
\text { uncertaintie } \\
\mathrm{s}: \text { uncertain } \\
\text { height but } \\
\text { shape / } \\
\text { function } \\
\text { known }\end{array}$ & \begin{tabular}{|c} 
Proven \\
existence \\
with known \\
height (or \\
assessable) \\
and \\
shape/functi \\
on known
\end{tabular} \\
\hline
\end{tabular}

Table 1: Description of the level of knowledge (and level of uncertainty) which might be associated to a wall belonging to a floor.

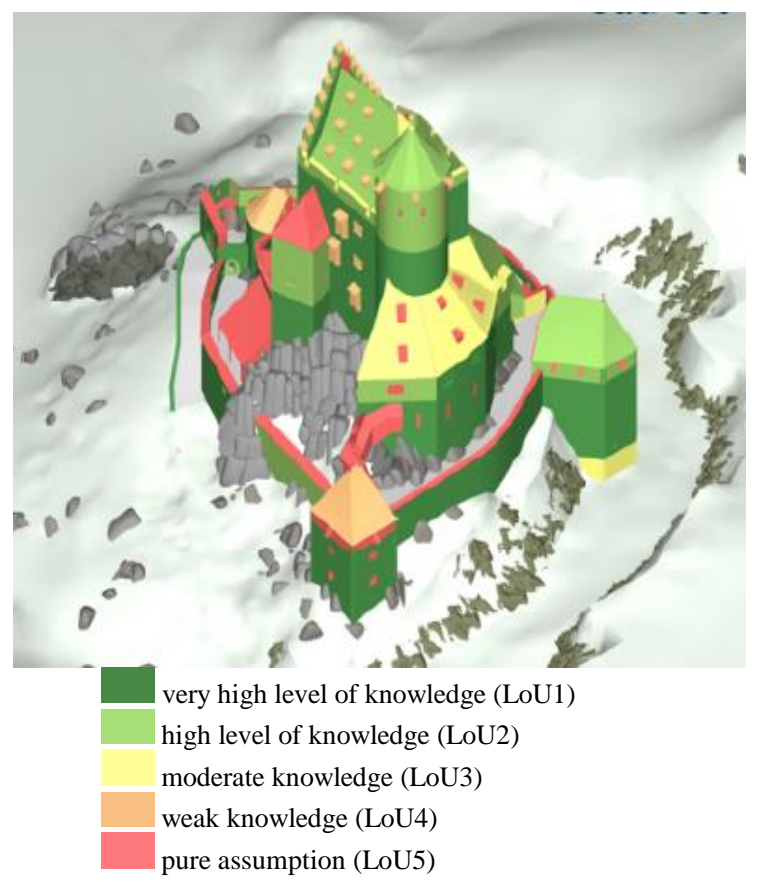

Figure 10: Uncertainty visualization based on five levels of uncertainty (LoUs), for the castle of Kagenfels, Alsace (southeast point of view)

\subsection{Horbourg-Wihr's castellum}

As there are only very few tangible elements for this castellum, the approach of restitution leaned on a large number of hypotheses by following four stages of Dell'Unto et al. (2013): data analysis, discussion, modelling, and finally validation, all this process being resumed in a loop. An emphasis was also put on the principle of transparency allowing to justify throughout the project the used hypotheses of restitution. The analysis, base of any form of interpretation, must be associated with the restitution. After analysing the different types of archaeological information, the various forms of uncertainties were studied. 
The decomposition in levels of uncertainties considered in this case is inspired from Dell'Unto et al. (2013), who suggest the use of 6 reconstruction levels:

1. Objective reconstruction or based on data analysis (laserscanning/ photogrammetric surveying)

2. Reconstruction by reference. Reconstruction refers to elements that are no longer available locally, but are confirmed by old documents and reliable references.

3 . Reconstruction by deduction. The reconstruction is based on repeated elements such as the columns of a temple which logically repeat themselves identically.

4. Reconstitution by comparison. Reconstruction relies on direct comparisons with similar archaeological remains found in the same geographical area.

5. Reconstitution by analogy of style. The reconstruction relies on the analogy with a known and recognizable theoretical model, like the Roman styles of the time and the architectural orders.

6. Hypothesis reconstruction. This is the most uncertain level of reconstruction, which is exclusively based on conjectures.

To ensure the understanding of the model, also for general public, only four levels of uncertainty were finally distinguished, as shown in Table 2:

- LoU1: Confirmed by excavations and archaeological work: relies on objective evidence of elements found during excavations and observed, or reliable historical sources and documents. The first and second levels ("objective reconstruction" and "reconstruction by reference" levels) proposed by Dell'Unto et al. (2013) were therefore grouped together in this level.

- LoU2: Restored by logical deduction. This level corresponds to the modeled parts located between two known elements. This concerns in particular the parts of the theoretical plan that have not been excavated but that have been drawn by extension between excavated parts.

- LoU3: Restored by analogy. This level brings together levels 4 and 5 ("reconstruction by comparison" and " reconstruction by analogy of style") proposed by Dell'Unto et al. (2013). Therefore the modelling of these parts relies on similar archaeological remains of the region, and on the Roman style.

- LoU4: Restituted by hypotheses. It is the lowest and most inaccurate level of certainty that concerns the modeled elements, because neither data nor information about these parts of the model exist. This concerns in particular the buildings inside the camp.

\begin{tabular}{|c|c|c|c|}
\hline \multicolumn{4}{|c|}{ Level of knowledge } \\
\hline $\begin{array}{c}\text { Pure } \\
\text { assumption } \\
\text { (LoU4) }\end{array}$ & $\begin{array}{c}\text { Moderate level } \\
\text { of knowledge } \\
\text { (LoU3) }\end{array}$ & $\begin{array}{c}\text { High level of } \\
\text { knowledge } \\
\text { (LoU2) }\end{array}$ & $\begin{array}{c}\text { Very high level of } \\
\text { knowledge } \\
\text { (LoU1) }\end{array}$ \\
\hline $\begin{array}{c}\text { Restituted } \\
\text { by } \\
\text { hypotheses } \\
\text { (buildings } \\
\text { inside the } \\
\text { camp) }\end{array}$ & $\begin{array}{c}\text { Modeled by } \\
\text { analogy (towers } \\
\text { and doors) }\end{array}$ & $\begin{array}{c}\text { Restored by } \\
\text { logical } \\
\text { deduction } \\
\text { (without } \\
\text { excavation }\end{array}$ & $\begin{array}{c}\text { Confirmed by } \\
\text { excavations and } \\
\text { survey (foundations, } \\
\text { passage slabs) }\end{array}$ \\
& & $\begin{array}{c}\text { results), (parts } \\
\text { between } \\
\text { excavations) }\end{array}$ & \\
\hline
\end{tabular}

Table 2. Description of the level of uncertainty which might be associated to the 3D model of the Castellum.

At this stage, the resulting 3D digital model can be used as an archaeological synthesis tool to identify directly what is known and not (Figure 11).

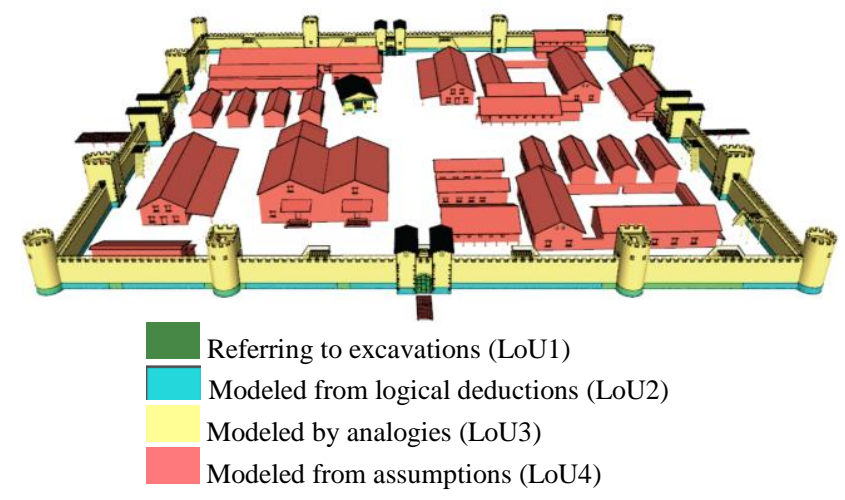

Figure 11: Uncertainty visualization based on four levels of uncertainty (LoUs). Case of the castellum of Horbourg-Wihr, Alsace.

To deepen the comprehension of the 3D model, several sheets have been completed for each of the main components of the model: internal buildings, double entrances, single entrances, rampart, temple, corner towers, intermediate towers and for the entrance towers.

These illustrated sheets include a description of the component, an exploded view of the component, the presentation of the data used to model the component and its origin, a bursting view of the component and the various sub-components, the main dimensions of the building, the interpretation that was made by the archaeologists, and finally a coloured view of the component according to the four LoUs in relation to the LoD of each component. Figure 12 shows a proposal for the modelling of the double entrance door. Table 3 illustrates the links between LoU and LoD for each sub-component.

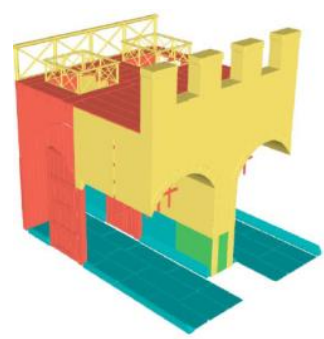

Figure 12. Detail of the double entrance model colorized according to the LoU defined in the Castellum project.

\begin{tabular}{|c|c|c|}
\hline Sub-component & LoD in 3D model & LoU \\
\hline Arcs & LoD2 & LoU3 \\
\hline Curtain & LoD1 & LoU3 \\
\hline Castellations & LoD2 & LoU3 \\
\hline Parapets & LoD3 & LoU3 \\
\hline Porticullis & LoD3 & LoU4 \\
\hline Paving stones & LoD2 & LoU2 \\
\hline Kerbstones & LoD2 & LoU2 \\
\hline Floor of the curtain & LoD3 & LoU4 \\
\hline Doors & LoD3 & LoU4 \\
\hline
\end{tabular}

Table 3. Links between LoDs and LoUs for sub-components of the double entrance.

\section{DISCUSSION}

The challenges of these projects, from an archaeological point of view, were to achieve the best possible restitutions of buildings, although knowledge and data were sometimes incomplete or missing. Both final rendered deliverables look impressive, but the degree of knowledge related to them is not 
comparable. Whereas the whole Castellum modeling was based mainly on assumptions, only some minor parts of the Kagenfels model are the product of subjective assumptions. Whereas for the castellum 4 levels of large classes were sufficient, for the Kagenfels the interval of uncertainty has been splitted into 5 levels of already well known objects.

In fact, although both projects used the decomposition in levels of uncertainties, the scales of knowledge are not the same for both castles. For the Kagenfels, the functional logic was in the center of the uncertainty assignment. Only components of the castle that must have existed have been represented. The highest level of uncertainty in the Kagenfels' model (LoU 5, qualified as "pure assumption") concerns the shape of the object but not its existence (wall, roof, etc.). The highest level of uncertainty in the Castellum's model (LoU4, qualified as "pure assumption") concerns the existence of the elements, like the buildings of the military camp. Indeed, we do not know anything about the internal spatial organization of the military camp.

If the decomposition in levels of uncertainties remains site dependent, the uncertainty visualization in a gradient of colored LoUs is an efficient solution and has been validated. With these visualizations, the 3D models can be considered as an archaeological synthesis tool allowing to identify directly the reliability of the reconstructed parts. This approach can be applied to every castle or historical monument under the condition that the table describing the level of knowledge (or LoUs) is joined to the model.

\section{CONCLUSION AND FUTURE WORKS}

The purpose of this paper was to propose a way to show clearly the reliability of the elements composing a 3D model obtained based on excavations and archaeological assumptions. Our approach accounts for the uncertainties of restitution related to data reliability. A hierarchical classification allows data to be organized according to their LoU. It considers levels of uncertainties ranging from from pure assumptions (highest LoU) to a very high level of knowledge (lowest LoU).

The longing to be transparent on the created model and to maintain a traceability of reasoning that guided restitution are two essential factors in an archaeological restitution process. Moreover, the efforts put to produce these representations for two castles paid off, because the resulting models provide a solid foundation for upcoming updates, in case of future on-site discoveries Indeed, it is important to remember that digital models produced are not definitive and that new excavations might lead archaeologists to review some hypotheses concerning the architecture of buildings already modelled.

\section{REFERENCES}

Barratt, R. P. (2016). Interpreting and presenting archaeological sites using 3D Reconstruction: Virtual exploration of the Xaghra Brochtorff Circle in Gozo, Dissertation, Faculty of Human, Social and Political Sciences. Pages: 128.
Benazzi, T., 2017. Restitution 4D du Château du Kagenfels par combinaison de l'existant et d'hypothèses archéologiques pour une visite virtuelle du site, Master Thesis, Insa Strasbourg, France.

Bertin, J. (2010) Semiology of Graphics: Diagrams, Networks, Maps Esri Press, 2011, 460 pp., ISBN: 978-1589482616

Dell'Unto, N., Leander, A., Dellepiane, M., Ferdani, D., Lindgren, S. (2013). Digital reconstruction and visualization in archaeology: Case-study drawn from the work of the Swedish Pompeii Project. 2013 Digital Heritage International Congress; doi: 10.1109/DigitalHeritage.2013.6743804, pp. 621-628

Fuchs, M. (1996). Le castellum : une étude lacunaire. Actes d'ARCHIHW 2-1996 : Horbourg-Wihr à la lumière de l'archéologie. Histoire et Nouveautés, pp. 135-145, 1996.

Gutierrez, D., Sundstedt, V., Gomez, F. Chalmers, A. (2006). Dust and light: predictive virtual archaeology. Journal of cultural Heritage 8, pp. 209-214.

Kensek, A. (2007). Survey of methods for showing missing data, multiple alternatives, and uncertainty in reconstructions. CSA Newsletter, Volume XIX No.3, pp. 1-29

Heissler, M (2007). Rapport de synthèse, ruines du château du Kagenfels, pages 4-46.

Landes, T., Grussenmeyer, P., Voegtle, T., Ringle, K.. (2007). Combination of Terrestrial Recording Techniques for 3D Object Modelling regarding topographic constraints. Example of the Castle of Haut-Andlau, Alsace, France. Int. Archives of Photogrammetry, Remote Sensing and Spatial Information Systems Vol. XXXVI-5/C53 ISSN 1682-1750 \& CIPA Int Archives for Documentation of Cultural Heritage, Vol. XXI2007 ISSN 0256-1840, pp. 435-440.

Nivola, T., 2017. Modélisation 3D du Castellum de HorbourgWihr et exploitation de la réalité augmentée pour une mise en valeur dans la trame urbaine contemporaine. Master Thesis, Insa Strasbourg, France.

Potter, K., Rosen, P., \& Johnson, C. R. (2012). From quantification to visualization: A taxonomy of uncertainty visualization approaches. IFIP Advances in Information and Communication Technology, 377 AICT, pp. 226-247.

Rodríguez-Gonzálvez, P., Muñoz-Nieto, A. L., DelPozo, S., Sanchez-Aparicio, L. J., Gonzalez-Aguilera, D., Micoli, L., Hejmanowska, B. (2017). 4D reconstruction and visualization of cultural heritage: Analyzing our legacy through time. ISPRS Archives, 42(2W3), Pages 609-616.

Zuk, T. Carpendale, S. et Glanzman, W. D. (2005). Visualizing Temporal Uncertainty in 3D Virtual Reconstructions, The 6th International Symposium on Virtual Reality, Archaeology and Intelligent Cultural Heritage. Pages 99-106. 